\title{
Idle, stricken, or retired: challenges in understanding media discourse on nuclear power
}

\author{
Desislava Cheshmedzhieva-Stoycheva*
}

\begin{abstract}
Being politically, economically, environmentally, and socially significant, the topic of nuclear power enjoys high interest in the media with its complex character. On the one hand, there is nuclear power used for civil purposes which is viewed as one of the most cost-efficient power generation ways, while on the other, there is nuclear power used for military purposes as a weapon of mass destruction. The focus of the paper is on the metaphors used in the presentation of issues associated with nuclear power. The main method of analysis is CDA and the corpus analysed is comprised of articles published in the American The New York Times, the British The Independent and the Bulgarian newspaper Dnevnik over the period of a month, i.e. March 2013. This study adds to current research on metaphors as it compares and contrasts the thinking patterns exhibited by three different cultures through their media discourse.
\end{abstract}

Key words: media discourse, NPP, metaphors, CDA

'Well you know boys, a nuclear reactor is a lot like women.

You just need to read the manual and press the right button.' - Homer Simpson

\section{Introduction}

Being politically, economically, environmentally, and socially significant, the topic of nuclear power enjoys high interest in the media with its complex character. On the one hand, there is nuclear power used for civil purposes which is viewed as one of the most cost-efficient power generation ways, while on the other, there is nuclear power used for military purposes as a weapon of mass destruction.

At the same time, accidents such as Chernobyl (1986) and Fukushima Daiichi (2011), to mention only two of the most devastating ones, ring the alarm bell not only locally but globally as well. All these nuances, in addition to many others, which each of us as a carrier of specific social experience has, make the topic of nuclear power a very interesting one to analyse especially from a comparative point of view.

The process of globalisation and the uninterrupted flow of information through various channels have led to transformations in the New Capitalism, presented

* University of Shumen, Department of English Studies, Shumen, Bulgaria 
by Klein (qtd. in Fairclough 2002: 163) as 'knowledge- or information-based' and dependent on new communication technologies and 'the associated salience of representations and images in the media' (op. cit.: 164). These transformations have resulted in a change in the nature of the global/ local dialectic (ibid.) and a big part of it is due to the role played by the media. People are instantly informed about all new developments happening worldwide as well as about all problems, failures or major crises. Based on their experience, as well as on the information they receive from the media, people are able to create, adapt or shift their perceptions and conceptualisations of a problem and appropriate what is new or different.

In this respect the media continue to reflect and at the same time influence and create versions of reality (see Fowler 1991; Cottle 2000). Research on the topic of the role of the media in the presentation of nuclear power issues only confirms that fact. Perko et al. (2011: 22) quoting Gamson and Modigliani, state that

political and public salience of issues is partly driven by the media coverage of these issues. When the media increase their attention to a given issue, the political elites jump on the bandwagon as well, by stating their opinion, asking parliamentary questions about the issue, tabling law proposals, or issuing executive orders.

Allan et. al (2000: 5) add that "public awareness and concern for environmental issues correlates with the relative amount of coverage being generated by the news organisations'. Beck (2001: 33) also acknowledges the important role of the media positioning them as:

a powerful lens that can publicly illuminate 'the unseen side-effects of industrial production' and help turn these into 'global ecological flashpoints'; and, in so far as these are not amenable to calculation and control, so the media spotlight contributes to the erosion of the very basis and legitimacy of the system itself. (qtd. in Cottle 2006: 123)

One of the powerful tools in the media frequently employed to convey even the slightest nuances of a topic are metaphors. Through their ability to conceptualise abstract phenomena with the help of more specific and down-toearth ones, metaphors can also create images and impressions of and attitudes to the matters discussed because, as stated by Gibbs (2008: 3), '[m]etaphor is not simply an ornamental aspect of language, but a fundamental scheme by which people conceptualize the world and their own activities.' At the same time, metaphors are ideological 'as they define in significant part what one takes as reality' (Hart 2008: 91) and they can 'contribute to a situation where they privilege one understanding of reality over others' (ibid.).

Another important feature of metaphors, which is also relevant for the study at hand, is the fact that they are based on experience and as we all share the common experience of being human, metaphors present similar cognitive patterns (Lakoff 1987: xii; Kovecses 2005: 6). Still, these similar perceptions 
are common only at the basic level or as presented by the so-called 'primary metaphors'. However, as explained further by Lakoff (2008) cultural specificities combined with these basic or primary metaphors 'give rise to different metaphor systems' (op. cit.: 26) which are culture specific and unique.

At the same time, following Fauconnier and Turner (2008: 53-54) the fact that 'conceptual products are never the result of a single mapping' and could be renewed or improved using new mappings fostered by new experiences which could be individual or group based should not be neglected. And, in order to make the dependency circle complete, Sharifian (2011) says that '[a]ttempts made to linguistically explicate conceptualisations may at best approximate our conceptual experiences but may never capture them in totality' (op. cit.: 10) and later on that '[d]ifferent levels and units of language such as speech acts, idioms, metaphors, discourse markers, etc. may somehow instantiate aspects of [...] cultural conceptualisations' (op. cit.: 12). Based on all this, it could be concluded that metaphors employed by the media discourses of the USA, the $\mathrm{UK}$, and Bulgaria would reflect both general as well as some culture specific nuances of the way people in the three countries perceive the problem of nuclear power plants. At the same time, the influence which globalisation might have had on the similarity of expressions in these linguistic devices should not be neglected.

By analysing the metaphors employed for the presentation of the topic of nuclear power plants, the study adds more insights to current research on the topic of metaphors as it compares and contrasts the thinking patterns exhibited by three different cultures through their media discourse.

\section{Corpus and methods of analysis}

The corpus of articles for this study is comprised of publications which appeared in the electronic versions of the American The New York Times, the British The Independent and the Bulgarian newspaper Dnevnik*

The reason to choose these three newspapers in particular was first, the fact that they are all considered serious press, and second, the fact that they enjoy high readership and have the reputation of trustworthy sources of information.

The study was conducted in 2013 with a special focus on the publications in

\footnotetext{
* The abbreviations of the newspapers used hereafter are as follows: The New York Times (NYT), The Independent (In) and Dnevnik (Dn). In addition, each analysed newspaper article is marked with a number of appearance in square brackets preceding the example and abbreviation of the newspaper followed by the date of publication in regular brackets after the example. The Bulgarian examples feature a prim after the square brackets, e.g. [4'] to signify that the example is translated from Bulgarian into English by the author of the study. Headlines of articles are marked by $/ \mathrm{h} /$.
} 
March as March $11^{\text {th }}$ marked the second anniversary of the accident in Fukushima and the analysis could help assess the influence of that event on international publications.

The total number of articles analysed is 700 (56 - New York Times, 135 Independent, 509 - Dnevnik) of which 67 articles were published in March (4 - NYT, 23 - In, 40 - Dn).

The main method of analysis applied is CDA as it is viewed as 'a democratic approach which is highly influenced by the context and takes ethic stance on social issues with the aim of improvement of society' (Huckin 1997: 78). CDA was also chosen because it is an integrated approach and applies different levels of analysis: 'the text, the discursive practices, which create it and the more general social context' (see Fairclough 1995; Huckin 1997: 78; Todorova 2015).

\section{Analysis \& Discussion}

As stated in the introduction, metaphors are a prolific device used in the media as they present information in a more interesting way. At the same time they could be both universal at a more generic level while culture specific at a more specific level. Metaphors on nuclear power plants, or on nuclear power for civil purposes, have not received significant attention by scholars especially from a comparative point of view. Still, some of the available research on metaphors in relation to the topic of nuclear power is referred to in this section.

A general metaphor viewed by Amory Lovins quoted by Lakoff and Johnson (2003: 157ff) regards the ways energy is obtained. As Lakoff and Johnson show there are two possible ways: a hard and a soft one and nuclear power plants are subsumed under the former:

The HARD ENERGY PATH uses energy supplies that are inflexible, nonrenewable, needing military defense and geopolitical control, irreversibly destructive of the environment, and requiring high capital investment, high technology, and highly skilled workers (ibid.)

It should be borne in mind that the context Lovins uses is military, therefore it is to be expected that the analysis of articles on nuclear power plants which are meant for civil use would not encounter exhibitions of this type of metaphor, a fact which is actually supported by the analysis of the corpus material. Still, these understandings of the nuclear issue are encountered in the debates proand against nuclear power in general, and the development of new nuclear power plants in particular.

Another metaphor which is analysed in relation to nuclear debate is the metaphor of the Machine.

A well designed machine is a beautiful thing: faithful, reliable, and obedient, 
performing difficult tasks without complaint. It is ethically neutral and free of emotions. Although it embodies a high degree of intelligent planning, it does not require extraordinary intelligence to use a machine for good or for ill. The machine will not balk; it will do as it is directed to do. (Edwards 1978)

He states that the input-output relationships which govern the machine are applicable for our understanding of a nuclear power station: the input is connected with raw materials while the output - with energy as well as with nuclear waste. The latter is not reusable and not subject to any natural processes which could make it less harmful thus making it 'the ultimate waste product'.

Nuclear power plants are buildings and as such it is to be expected that the metaphors used will involve Lakoff's (2001) concept of a building as a person. As he states 'We see features - eyes, nose, and mouth - in their windows'. Homer Simpson's words quoted at the beginning of this paper confirm the existence of this concept in terms of power plants as well. De Clarke (1983) provides further clarification of that metaphor as both women and nuclear power plants are meant to please men and 'generate more male power'. Caputi (1991) views the same metaphor from a feminist point of view but her analysis will not be dealt with here as it is not relevant to the current study. What is relevant for the analysis at hand, however, is the association between a plant and a person.

In a modified and more generalised version, the metaphor most frequently employed by the analysed newspapers could be formulated as Nuclear Plants are Living Organisms. Thus, when plants are presented as humans, they have their own life cycle: they age, they grow old, and they retire or are retired:

[1] Output from the two has sometimes forced the Columbia Generating Station in Washington State, the region's only surviving nuclear reactor, to cut back its production. [...] Adding to the clean energy industry's cannibal behavior, wind farms are being built in places where there is lots of wind but not much demand for power, some experts argue. [...] Exelon, he said, is "seeing this tipping point developing" when several of its zero-carbon reactors may have to be retired because wind power is suppressing those prices around the clock, and at some hours producers must pay the grid operator if they put energy on the grid (NYT/ 27.12.13).

In this example a nuclear reactor is presented as surviving and the association comes from the field of endurance, stamina, and skill, all qualities necessary in a hostile environment exemplified by the strife sustainable energy, in this case - wind energy. The preference shown to renewable energy is expressed through yet another metaphor which presents a wind farm as a vicious human exhibiting cannibal behavior and being an oppressor.

The example makes a very visual representation of the clash between the different types of energy. At the same time, in addition to being human, wind energy is presented as a bird and the concept of a suitable place or conditions proper for its birth (though artificial ones) is presented through an incubator. 
Using the same domain, the industry itself is presented as a 'chicken'. Here we see instances of the general metaphor Creation is Birth as proposed by Lakoff and Johnson (2003: 76) which in this case is more like hatching.

Still more interesting, later on the bird actually acquires the features of a human child and a grown up individual in one and the same example:

[2] [wind energy] Mr. Nickles, who was a senator when the first production tax credit was passed, said that it was meant to be an incubator for a fledgling industry. Now, he said, "This child is ready to go to college." [NPP] "With 20 years and 60,000 megawatts in the ground, this is a mature industry," David C. Brown, an Exelon lobbyist, said of the industry. "It's time we declare victory and celebrate our success." (NYT/ 23.12.13).

Although the last example does not fall into the specific subject area of study, it does comprise the broader topic of energy generation and the power generating industry. The comparison provides interesting thinking patterns which show some nuances in the perception of two of the methods of power generation. Looking at the examples from the corpus of the study, there are further exhibitions of the metaphor Power Plants are Living Organisms applied to nuclear power plants:

[3] Hinkley Point: Britain's second nuclear age given green light as planning permission is approved for first of new generation atomic power stations /h/ [...] The Energy Secretary, Ed Davey, gave the go-ahead to build a new plant at Hinkley Point in Somerset to the French energy giant EDF, which already runs eight of Britain's first generation nuclear power plants, now rapidly ageing. (In/ 19.03.13); [4'] Selected lies in the repertoire of the theatrical performance New Nuclear Power Station /h/ Both Mr. Saxe-Coburg-Gotha and Mr. Stanishev (who plays the hen and who the cock is irrelevant) laid a big addle egg. Now they are cackling that the addle egg is a golden one and are trying to make us try to hatch it. (Dn/ 16.03.13).

The idea of birth and development is hinted additionally through the use of the lexeme generation, also suggestive of the fact that nuclear plants could reproduce and improve within their kind. Bulgarian media discourse offers an example, i.e. [4], where a nuclear power station is presented as an addle egg which has been laid by the two PMs (also presented with units from the lexico-thematic field of a hencoop) and which it is up to the population to hatch. As could be seen the idea of a hencoop is developed through nouns (addle egg, golden egg, hen, cock) and through verbs (lay, cackle, hatch) as well. There is also an intertextual reference to the fairy tale about the hen with the golden eggs, where the eggs were of gold and quite expensive. The truth, however, is that the egg in this case is rather an addle than a golden one, therefore implying the negativism of the journalist toward the project for the development of a new nuclear power station in Belene proposed by two different Bulgarian Prime Ministers of two different governments - that of the National Movement Simeon the Second led by the then PM Simeon Saxe-Coburg-Gotha (there were debates around NPP Belene in 2004) and that of the Socialist government led by Sergey Stanishev (he re- 
opened the project in 2008). The implicit suggestion is that rather than being something valuable and quite expensive, the project is rotten and it stinks (both literally referring to an addle egg, but also figuratively used for a project whose character is quite dubious), therefore such an endeavor is good for nothing.

Similar is the idea behind another example from the Bulgarian media which also employs the Living Organism metaphor, however, in this case, the plant is presented as a horse. The focus is on the games politicians play and the hidden agendas they follow:

[5] Belene - the Trojan horse of Moscow? /h/ [...] The development of NPP Belene could happen only at the expense of the Bulgarian tax payers - the reason for that is quite simple: no private investor would let him/herself in the construction of an electrical plant whose production could be sold either on the Bulgarian or on the international market. A very convincing proof of that is the suspension of part of the generating capacities of NPP Kozloduy - a result of the dramatic drop in consumption and the lack of external markets (Dn/ 09.06.13)

What articles of this type do, is show the inconsistency in the development of a new power station: due to the lack of market for its energy and the need for substantial investments. The intertextual reference to The Aeneid by Virgil or Odyssey by Homer is suggestive of the policy followed by the Bulgarian Socialist Party who is openly pro-development of a new nuclear plant and its 'servitude' to Russia. The comparison is also quite obvious: it is suggested that Russia wants to undermine Bulgarian economic stability by involving the country into a project which would cost a lot and would not be used.

Example [4'] is also telling of another metaphor used in the presentation of the topic of nuclear power plants - the metaphor of Theatre. Probably influenced by the metaphor Politics is a Theatre, the debatable issue about the establishment of a new power plant is presented as a play in which the main characters are political figures. The idea once again is that it is politicians who pull the strings; they are the ones to make the final decisions. The latter is non-metaphorically stated in The Independent and in The New York Times:

[6] the sole conclusion is that politics, not concerns over the environment or energy, will decide whether or not £14bn will be spent at Hinkley Point” (In/ 21.03.13); [7] This is about whether we want a nuclear industry or don't we. That is the question. Only the politicians can decide (NYT/ 15.03.13).

Continuing on the trend of personifying nuclear energy, there are examples in which nuclear energy is metaphorically presented as the nursing milk necessary for a country to grow. This idea is presented mainly in articles on Germany's decision to close most of their nuclear reactors. The metaphor is linguistically activated through the use of the verb wean: [8] 'The new government has pledged to focus on weaning the country from nuclear power' (NYT/ 17.12.13); [9] 'She [Angela Merkel] is trying to wean her country from nuclear power' 
(NYT/ 15.12.13). In this case the country, Germany, is actually the child who needs to grow up and enter the next stage of development and in order to do that the child has to be weaned from the mother's milk and given more nourishing food.

Nuclear plants are also presented as idle:

[10] A Nebraska nuclear plant that has been idle for nearly three years because of flooding and a series of safety concerns has been cleared to begin operations again (NYT/ 17.12.13); [11] The new target, however, is based on Japan's never turning on any of its scores of idled plants, despite the government's continued push to bring many of them back online (NYT/ 15.11.13)

At the same time, the last example uses another metaphor, mentioned above: Nuclear plant as a Machine. In this case media discourse has resorted to the domain of computer science and has used an idiom from that field to describe the process of reactivating nuclear plants.

Plants are also presented as susceptible to illnesses (including mental ones) or body injuries:

[12] Removing Fuel Rods Poses New Risks at Crippled Nuclear Plant in Japan /h/ [...] (NYT/ 10.11.13); [13] Duke Energy is weighing the issue of how to replace the power generated by its troubled Crystal River nuclear plant in Florida [...] ailing plants like Crystal River are less likely to survive than they once were, one analyst suggested on Wednesday (NYT/ 06.02.13); [14] This year, utilities have announced the retirement of four reactors, bringing the number remaining in the United States to 100. (NYT/ 14.06.13); [15] The nuclear industry is wrestling with that question as it tries to determine whether problems at reactors, all designed in the 1960s and 1970s, are middle-aged aches and pains or end-of-life crises (NYT/ 14.06.13); [16] [...] a rare tour through the radioactive carcass of the Daiichi nuclear plant [...] But the cleanup, two years after the plant was pummeled by a huge earthquake and tsunami, is plagued by a buildup of irradiated water [...] (In/ 06.03.13); [17] They displayed a bravery few can comprehend, yet very little is known about the men who stayed behind to save Japan's stricken nuclear plant. [...] an earthquake and tsunami crippled the Fukushima Daiichi nuclear plant on 11 March 2011 [...] (In/ 02.03.13).

As could be seen from the examples, plants experience pain, sufferings, and could be affected even by plague, which in itself is suggestive of the ultimate phase of one's life - death. Following this general line of thought nuclear plants also die and what is left is their carcasses as in [16] above.

The idea of death is communicated explicitly through the use of participles such as stricken in [17] above, as well as through noun phrases used in other examples from the corpus, like: [18] nearing the end of their lives (NYT/ 11.11.13); verb phrases like: phase out, gerunds: phasing-out (In/ 16.09.13); expressions: [19] nuclear energy has been de facto dead for decades, now it is also getting de jure dead, with its outlawing in Germany and (even in the best case) severe curtailing in Japan. (NYT/ 03.11.13) or [20'] Rosatom does not put a cross over 
NPP Belene /h/ (Dn/ 28.02.13).

Consistent with the metaphor presenting renewable energy as a child, energy sources could also be adopted: [21] The graph above charts the contributions played by improved efficiency and adoption of renewable electricity sources as well as hydrogen fuel cells (with the hydrogen generated with renewable energy) (NYT/ 12.03.13). And a nuclear plant, being human and having human needs could also be our neighbour: [22] Californians Consider a Future Without a Nuclear Plant for a Neighbor /h/ (NYT/ 25.07.13).

Another noun phrase used to refer to the French company EDF who is in charge of the development of the newest nuclear plant in the UK, is an energy giant referring to its prominence, competence and status. That same phrase is frequently used in Bulgaria as well in reference to big companies in the field; however, such uses have not been allocated in the corpus.

The analysed Bulgarian newspaper is quite conservative in the use of metaphors in its presentation of nuclear power plants. In the Bulgarian psyche nuclear plants could be rehabilitated (meaning that they have been ill): [23'] That's why the most practical and cheapest way for the development of nuclear power in Bulgaria is the successful rehabilitation of reactor 5 and 6 of NPP Kozloduy (Dn/ 28.11.13); [24'] TPP AEC - Galabovo, TPP Contour Global and TPP Maritsa Iztok 2 are rehabilitated $(\mathrm{Dn} / 16.03 .13)$. Or, they are described as out of exploitation: a phrase which could be considered a dead metaphor or a set expression:

[25] Members of the Euro Parliament approved the budget to decommission the old units in NPP Kozloduy /h/ [...] The three countries (Lithuania, Slovakia and Bulgaria) used old nuclear reactors which were considered by the international community too old to be effectively modernised so that they could meet the minimal required safety standards (Dn/20.03.13).

Plants could also be restored to life: [26'] The Government will revive NPP Belene once again $/ \mathrm{h} /(\mathrm{Dn} / 30.11 .13)$.

Another metaphor that is very frequently used in the articles on nuclear power is the War metaphor activated through the use of verbs such as struggle, kill off, and nouns like victory, fleet, battle, among others:

[27] New Energy Struggles on Its Way to Markets /h/ [...] at the moment, two of those largest sources, nuclear and wind power, are trying to kill each other off. (NYT/ 27.12.13); [28] Hinkley Point would be the first nuclear power station to be built in Britain in nearly two decades. The government has portrayed the project as crucial to keeping the lights on in Britain and to reducing carbon emissions from electricity generation as the current aging fleet of nuclear power stations and coal-powered power plants are phased out in the next few years. (NYT/ 02.12.13); (NYT/ 15.03.13); (NYT/ 19.03.13); [29] The campaign will come as a further blow to the Government's energy policy as it struggles to put private-sector funding in place for a new foray into nuclear 
power generation at Hinkley Point in Somerset. (In/ 01.04.13); [30] Two years on the deadly battle to save Fukushima from an invisible, odourless enemy goes on $/ \mathrm{h} /[\ldots]$ It is a battle waged with robots, state-of-the-art engineering and some of the most advanced filtering equipment on the planet, and by the time it is finished, the world will be half way through the 21 st century $(\mathrm{In} / 06.03 .13)$.

Radiation, as part of the process of electricity generation, is also described within the terms of war; it is the enemy who is difficult to fight because of his/ her odourless and invisible character.

Sports metaphor, which is quite characteristic of political discourse, such as Politics is a Game, is also employed by the media when talking about nuclear power:

[31] Energy companies announced this year that five nuclear reactors would be closing or not reopening, and the owners blamed competition from natural gas and wind. In the Pacific Northwest, wind and hydroelectricity - neither of which produce carbon - are sparring to push each other off the regional power grid (NYT/ 27.12.13); [32] Wind Power Developers Race Clock to Secure Subsidy /h/ [..] "What we see right now is a race to the finish line, where we're trying to get projects signed," said Mark Albenze, chief executive of the Wind Power Americas unit of Siemens Energy (NYT/ 23.12.13); [33] The loss of power at the nuclear plant, which was knocked out by the Japanese tsunami in 2011, shut down cooling systems used for some of the plants reactors ( $\mathrm{In} /$ 21.03.13), see also [15].

As the examples show, while nuclear power is more or less described within the terms of wrestling or boxing, thereby sports using not only skill but strength as well, the new, renewable types of energy are presented as runners where speed and endurance are the necessary ingredients.

Another nuance of the sports metaphor is presented through associations with gambling, or more specifically through associations with a game of poker:

[34] Convinced by Hinkley's business model, Japanese and Spanish energy groups would then follow suit with a wave of new civil nukes lighting up the UK. (In/ 28.03.13); [35] With such an emphasis on the development of shale gas projects in the Budget, and notwithstanding power plant capacity cuts such as SSE unveiled today, it seems that the Treasury believes there are alternatives to nuclear, which weakens EDF's hand. [...] However, the future of Britain's energy supply should not be decided by a soon-to-be-forgotten, completely pointless, petty political win. [...] By playing a political game that has so little obvious long-term political benefit, George Osborne and his team at the Treasury could end up undermining their entire growth strategy. (In/ 21.03.13); [36'] While I was out and about two or three days tending into my own things, the progressive powers have raised their voices - they wanted to know where the adversaries of NPP Belene were and why they haven't opposed the introduction of the American Westinghouse in the Bulgarian nuclear poker (Dn/ 28.11.13); [37] Although envisioned as a big bet on Britain's clean-energy future, the project has been bogged down in months of dickering between the British government and EDF Energy, the French state-controlled power company that is supposed to oversee construction and eventually operate the plant. (NYT/ 15.03.13) 
Apart from presenting the general trend in nuclear energy as a game of cards which in the British example is more like a Belote, while in the Bulgarian one it is obviously a poker due to its gambling nature, there is another metaphorical presentation that is worth mentioning: nuclear plants are associated with water: [38] EDF subsidy to put UK on nuclear path /h/ [...]The Government is understood to have agreed a 35-year subsidy to French energy group EDF to build the first in a new wave of nuclear power stations ( $\mathrm{In} / 10.03 .13)$. The development of new nuclear plants is presented as a wave, suggesting that they will cover the world as they will be built in big numbers, at the same time leaving a pool of water unattended makes the water stagnant and could lead to the pool turning into a bog. The association with the project of a new power station in Hinkley is thus similar to a swamp (see example [37]).

In addition, projects could be frozen and unfrozen, which is again suggestive of nuclear plants' association with water: [39'] Unit 7 in NPP Kozloduy has not shifted the topic from the unfreezing of NPP Belene $/ \mathrm{h} /(\mathrm{Dn} / 28.11 .13)$

Last but not least, nuclear reactors are also presented as a cure for chronic disease: [11] The prime minister of Pakistan, Nawaz Sharif, announced this week that China would help build two nuclear power reactors in Karachi, a port city with chronic electricity shortages (NYT/ 27.11.15).

\section{Conclusion}

Despite the sociopolitical differences observed in the three countries, the metaphors activated by the three analysed newspapers show surprising similarity.

The most prolific metaphor in the language of the three analysed newspapers is the metaphor Nuclear Plants are Living Organisms with various realisations some of which focus on the understanding of a nuclear plant as a human, who is born, who is young and then old, gets ill from time to time, could suffer mental illnesses, could be retired, could also reproduce and could be someone else's neighbour. These metaphorical realisations are characteristic mostly of the discourse of the analysed British and American newspapers.

The Bulgarian newspaper employs the metaphor an NPP is a Human only in the set expression used in Bulgarian to refer to a decommissioned plant or in sporadic cases when the reference is to an old reactor which is brought back to life. Another nuance of the metaphor NPP is a Living Organism realised in Bulgarian media discourse presents a plant as an egg (addle and golden) or a horse. The bird metaphor is also encountered in the analysed American newspaper. The same newspaper also presents nuclear power as the nursing milk for the country (Germany in that case). 
Another metaphor resorted to mostly by the British and the American analysed newspapers is the war metaphor activated through the use of verbs such as struggle, kill off, nouns like victory, fleet, battle, etc.

Nuclear power is also described through the use of a sports metaphor, where the nuclear power is described within the terms of wrestling or boxing, thereby sports using not only skill but strength as well, while the new, renewable, types of energy are presented as runners where speed and endurance are the necessary ingredients.

A nuance of the sports metaphor employed by the Bulgarian and the British newspaper is Nuclear Power is Gambling, or more specifically a Game of Cards. In the Bulgarian newspaper the game is poker, while in the British one, it is Belote.

Another field resorted to in order to explain nuclear power is water. Nuclear power plants and the projects associated with them could be frozen or unfrozen in the Bulgarian psyche, while in the American psyche they could be bogged. In the British psyche this conceptualisation is presented through the idea of a wave of nuclear power stations that would be built.

All these metaphors contribute to the more vivid presentation of the topic and at the same time show similarity in the way the three different nations perceive nuclear plants, which is interesting given the differences in political and economic development.

Having said that, the current study is but a small particle of a possible future project on nuclear power metaphors which could broaden the variety of newspapers covered in the corpus as well as extend the period of analysis and thus broaden the scope of metaphors employed by the three media discourses.

\section{References:}

Allan et. al 2000. Allan S., Adam B., Carter C., U. Beck, Environmental Risks and the Media. London: Routledge, 2000.

Caputi 1991. Caputi J. "The Metaphors of Radiation, or, Why a Beautiful Woman is Like a Nuclear Power Plant”. Women's Studies International Forum 14(5). 1991. 423-442.

Cottle 2000. Cottle S. (ed.). Ethnic Minorities and the Media: Changing Cultural Boundaries. Buckingham, Philadelphia: Open University Press, 2000.

Cottle 2006. Cottle S. Mediatized Conflict: Developments in Media and Conflict Studies. New York: OUP, 2006.

De Clarke 1983. De Clarke. 'Why is Beauty on Parade?' 1983. <http://www.hartford-hwp. com/archives/45a/250.html $>$. (Accessed on 11 January 2016).

Edwards 1978. Edwards G. "A Metaphorical Framework; The Ecosystem versus the Machine. Part One of the CCNR Final Submission to the Ontario Royal Commission on Electric Power Planning”. 1978. <http://www.ccnr.org/ metaphor. html>. (accessed on 11 January 2016). 
Fairclough 1995. Fairclough N. Critical Discourse Analysis: The Critical Study of Language. London, New York: Longman, 1995.

Fairclough 2002. Fairclough N. "Language in New Capitalism". Discourse and Society 13 (2). London, Thousand Oaks, New Delhi: SAGE, 2002. 163-166.

Fowler 1991. Fowler R. Language in the News: Discourse and Ideology in the Press. London and New York: Routledge, 1991.

Gibbs 2008. Gibbs R. W. Jr. "Metaphor and Thought: The State of the Art". In Gibbs R. W. Jr. (ed.). The Cambridge Handbook of Metaphor and Thought. Cambridge, New York, Melbourne, Madrid, Cape Town, Singapore, São Paulo: Cambridge University Press, 2008. 3-16.

Gilles, Turner 2008. Gilles F., M. Turner. "Rethinking Metaphor”. In Gibbs R. W. Jr. (ed.). The Cambridge Handbook of Metaphor and Thought. Cambridge, New York, Melbourne, Madrid, Cape Town, Singapore, São Paulo: Cambridge University Press, 2008. 53-54.

Hart 2008. Hart Ch. "Critical Discourse Analysis and Metaphor: Toward a Theoretical Framework". Critical Discourse Studies 5(2). 2008. 91-106. <http://uhra.herts.ac.uk/ handle/2299/ 4862>. (Accessed 11 January 2016).

Huckin 1997. Huckin Th. N. "Critical Discourse Analysis”. In Miller T. (ed.). Functional Approaches to Written Text: Classroom Applications. Washington: English Language Programs, 1997. 78-92.

Kovecses 2005. Kovecses Z. Metaphor in Culture. Universality and Variation, Cambridge, New York, Melbourne: CUP, 2005.

Lakoff 1987. Lakoff G. Women, Fire, and Dangerous Things: What Categories Reveal about the Mind. Chicago: University of Chicago Press, 1987.

Lakoff 2001. Lakoff G. "Metaphors of Terror". 2001. <http://www.cse.buffalo. edu/ rapaport/575/ F01/lakoff.on.terrorism.html>. (Accessed 7 January 2016).

Lakoff 2008. Lakoff G. "The Neural Theory of Metaphor”. In Gibbs R. W. Jr. (ed.). The Cambridge Handbook of Metaphor and Thought. Cambridge, New York, Melbourne, Madrid, Cape Town, Singapore, São Paulo: Cambridge University Press, 2008. 17-38.

Lakoff, Johnson 2003. Lakoff G., M. Johnson. Metaphors We Live By. London: The University of Chicago Press, 2003.

Perko et. al 2011. Perko T., Turcanu C., Geenen D., Mamane N., L. Van Rooy. "Media Content Analysis of the Fukushima Accident in two Belgian Newspapers". OPEN REPORT of the Belgian Nuclear Research Centrum SCK•CEN-BLG-1084. Nuclear Science and Technology Studies (NST). Programme for Integration of Social Aspects into Nuclear Research (PISA), Belgium. 2011.

Sharifian 2011. Sharifian F. Cultural conceptualisations and language: Theoretical framework and applications. Amsterdam, Philadelphia: Benjamins Publishing B. V., 2011.

Todorova 2015. Todorova R. Insights in Text Linguistics. From Theory to Practice. Shumen: Konstantin Preslavsky University Press, 2015. 